\title{
NEWS
}

\section{Medical insights from mummies}

The health status of people living in ancient times has remained under wraps - quite literally so in the case of Egyptian mummies. But thanks in part to developments in medical imaging technologies, various research teams have scanned mummies and gained insight into which diseases may have most troubled these populations.

Just this past February, a paper reported that computed tomography (CT) scans of nine mummified ancient Egyptians of high social status showed signs of atherosclerosis, indicating that they may have indulged too much during ceremonial banquets (Lancet 375, 718-719, 2010). The field is generating enough data that the American Association of Anatomists helped organize a minisymposium on the subject of physical anthropology at the Experimental Biology meeting in California. Experts gathered to review, among other topics, the information they've collected on everything from calcified blood vessels to dental damage seen in mummies.

'Palaeopathological research' is flourishing, and it's shedding light on the evolutionary history of disease. "Thus, it has high relevance for modern clinical medicine, too," says Frank Rühli. As head of the Swiss Mummy Project at the University of Zurich, Rühli has been fascinated by the medical insights offered by studying preserved ancient remains from Egypt and elsewhere. Rühli, whose data were presented at the symposium, and his collaborators have obtained CT scans of Egyptians such as that of this approximately 30-year-old male called Nacht-ta-Netjeret (shown in background), dated to circa AD 150 and found in El-Hibe.

The CT cross section (below) of lower limbs shows the calcified posterior tibial artery of an adult male dated back to around $1000 \mathrm{BC}$ and found near the ancient city of Thebes. Rühli often sees severe forms of atherosclerosis in ancient Egyptian mummies; thus, lifestyle and genetic factors contributing to this disease may have been similar to what they are nowadays. A review of the literature by his group reported that dental and pulmonary diseases are very frequently found in ancient Egyptian mummies (Homo 60, 405-427, 2009).

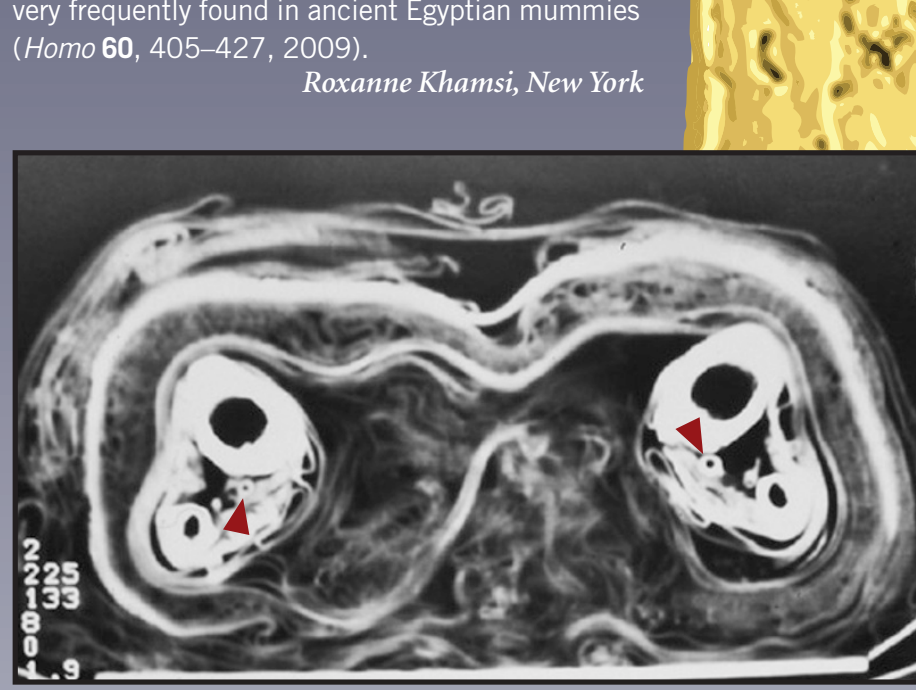

